\title{
Modelo de análisis de estructuras narrativas infantiles en niños de 3-4 años
}

Recibido: abril 2014

\author{
Maite MONFORTE MARESMA \\ Ignacio CEBALLOS VIRO \\ Universidad Internacional de La Rioja, \\ Dpto. de Lengua, Literatura y sus Didácticas \\ maitemoma@yahoo.es \\ ignacio.ceballos@unir.net
}

Aceptado: julio 2014

\section{RESUMEN}

El presente estudio compara las diferencias en las estructuras narrativas de los relatos orales producidos por un grupo de niños de entre tres y cuatro años. Exploramos la forma en que los niños organizan sus narraciones para comprender cuál es su concepción de relato, determinando la organización textual y la complejidad narrativa. Revisamos, de forma crítica y constructiva, tres modelos distintos de evaluación de la estructura narrativa en las producciones cuentísticas orales infantiles (Applebee, 1978; Landaeta et al., 2009; Heilmann et al., 2010), de los que nos hemos servido para analizar exhaustivamente nuestro corpus. Tras advertir ciertas limitaciones en estos modelos, elaboramos un modelo alternativo de análisis que nos permite, por una parte, describir de forma detallada las características identificadas en las narraciones que constituyen nuestro objeto de análisis, ofreciéndonos una rica descripción de las habilidades orales de los niños; y, finalmente, postular un modelo de estudio de estructuras narrativas que mejor se adapta a la franja de edad de tres a cuatro años.

Palabras clave: Narración oral, estructuras narrativas, creación literaria, Educación Infantil.

\section{Children's Narrative Structure Analysis Model in 3-4 Year-Olds}

\begin{abstract}
The present paper compares the differences in the narrative structures of oral stories produced by a group of three-four year old children. We explored how children organize their narratives in order to understand their narrative concept, determining the textual organization and narrative complexity. We review, in a critical and constructive manner, three different evaluation models of narrative structure in tales produced by children (Applebee, 1978; Landaeta et al., 2009; Heilmann et al., 2010). They served us to thoroughly analyze our corpus. Having noticed certain limitations in these models, we propose an alternative analytic scheme that allows us, first, to describe in detail all characteristics identified in the narratives that constitute our sample, offering an accurate
\end{abstract}


portrait of the oral skills in children; and, finally, it allows us to apply a model of narrative structures best suited to the age group of three to four year-olds.

Key-words: Oral narratives, narrative structure, literary creation, Preschool education, Kindergarten.

\section{Modèle d'analyse de structures du récit enfantin dans 3-4 ans}

\section{RÉSUMÉ}

L'étude suivante compare les différences entre les schémas narratifs de récits oraux produits par un groupe d'enfants entre trois et quatre ans. Nous avons exploré la forme dont les enfants organisent leurs narrations afin de comprendre quelle est leur conception du récit, tout en déterminant l'organisation textuelle et la complexité narrative. Nous avons révisé de façon critique et constructive, trois différents modèles d'évaluation et de schéma narratif dans les récits oraux des enfants (Applebee, 1978; Landaeta et al., 2009; Heilmann et al., 2010) qui nous ont servi à analyser minutieusement les productions orales des enfants. Après avoir avisé de certaines limitations sur ces modèles, nous avons élaboré un modèle alternatif d'analyse qui nous permet, d'une part, décrire minutieusement les caractéristiques identifiées dans les narrations qui constituent notre modèle d'analyse, tout en nous offrant une riche description des habilités orales des enfants et finalement, préconiser un modèle d'étude des schémas narratifs qui puisse le mieux s'adapter à la tranche d'âge entre trois et quatre ans.

Mots-clé: Narration orale, schéma narratif, création littéraire, maternelle.

Sumario: 1. Introducción. 2. Antecedentes teóricos y modelos usados para calificar y clasificar las narraciones infantiles. 2.1. Las estructuras de las narraciones de applebee. 2.2. La escala de desarrollo narrativo de landaeta-coloma-pavez. 2.3. El esquema de puntuación narrativa (narrative scoring scheme) de heilmann-miller-nockerts2.4. Complejidad y organización narrativa desde la perspectiva de los géneros (shiro). 2.5. Discusión de los modelos. 3. Nuestro corpus. 3.1. Objetivo, población y muestra. 3.2. Metodología de experimentación en el aula. 3.3. Técnicas de recogida de datos y su análisis. 3.4. Aplicación de los modelos de análisis narrativo sobre nuestro corpus. 3.4.1. Estructuras de las narraciones infantiles: applebee 3.4.2. Aplicación del modelo de landaeta-coloma-pavez. 3.4.3. Aplicación del modelo de heilmann-miller-nockerts. 4. Análisis de relatos infantiles. 4.1. Operacionalización de conceptos. 4.2. Indicadores. 4.2.1. Comprensión y control del género narrativo.. 4.2.3. Complejidad... 4.2.6. Habilidad discursiva y pragmática, 4.2.7. Soltura. 5. Propuesta de modelo de análisis. 5.1. Contraste de datos. 6. Conclusiones e implicaciones didácticas. 7. Bibliografía

\section{INTRODUCCIÓN}

La pregunta acerca de cuál es la relación que se establece entre los niños y la literatura no puede esperar una respuesta completamente satisfactoria si no consideramos la literatura que los niños crean. Atender a sus creaciones narrativas supone en cierta manera introducirnos dentro de la mente de los niños; analizándolas, podemos comprender algo sobre qué piensan cuando escuchan algún 
cuento, o cuál es su concepción del relato. En estas páginas nos sumergiremos, pues, en la cabeza de los niños de 3 y 4 años que nos contaron sus cuentos, para tratar de discernir sus ideas acerca de las estructuras narrativas y determinar su capacidad para producirlas.

El proceso por el cual se adquieren las habilidades narrativas resulta de una complejidad en la que se combinan diferentes factores. Muchas investigaciones se ocupan de este proceso, aunque cada una de ellas lo hace desde aspectos concretos -innatos, adquiridos, biológicos, socioculturales, etc.-. Todos estos estudios tienen en común la búsqueda de por qué un niño que no habla al nacer, enseguida se convierte en un hablante que puede comunicarse con los demás de forma exitosa. “[...] los relatos reportan, construyen, organizan, expresan, reflejan nuestras experiencias, lo cual explica la alta frecuencia de este género discursivo en todo tipo de contexto comunicativo" (Shiro, 2011: 7).

El pensamiento y las habilidades narrativas en la infancia evolucionan a una gran rapidez. La literatura dirigida a los niños desarrolla el aprendizaje de las formas narrativas en los más pequeños, a través de las cuales se adquieren maneras simbólicas de representar la realidad y reflejan una forma básica de dar sentido al mundo y a la experiencia. Hay quienes sostienen que la adquisición de estrategias y habilidades narrativas refleja una estructura fundamental de nuestra mente (Vygotski, 1981; Bruner, 1988). Así, cualquier niño aprendería de forma veloz que el acto de narrar es una técnica utilizada habitualmente por las personas para comunicarse e imaginar mundos posibles.

Partiendo de que la narración oral es una actividad permanente en nuestra vida, y una necesidad comunicativa entre los seres humanos, consideramos de gran importancia el conocer la forma en la que se estructuran las narraciones infantiles, pues nos muestran su complejidad en lo que se refiere a la organización o estructura. Dicha complejidad se haría evidente a través de los elementos que intervienen en una historia, aumentando de número y diversificándose con la edad. Este será el propósito de nuestro estudio: clasificar los relatos de una significativa muestra de niños según distintos modelos de análisis narrativo, con el fin de entender cómo los niños gestionan la complejidad en las historias que cuentan.

A lo largo de todo el artículo utilizamos los conceptos de narrativa y relato en el sentido que se le ha dado desde el ámbito de los estudios literarios y la narratología (Propp, Todorov, Genette, etc.). Por ello, entendemos por estructura de un relato la organización de su trama y de su fábula, el incardinamiento de sus personajes o actantes y el resto de elementos que configuran esa narración. Asimismo, admitimos en este trabajo como narración cualquier emisión lingüística infantil (inducida o espontánea) en la que existe una sucesión de acontecimientos articulados en torno a un conflicto.

Comenzaremos con una exposición de algunos de los principales modelos precedentes de análisis narrativo infantil, que contrastaremos y discutiremos; a continuación, exponemos el procedimiento de recogida y análisis de la muestra de 
relatos que hemos estudiado; posteriormente, explicamos nuestra propuesta de modelo de clasificación de las narrativas infantiles, en el marco de los estudios previos; y, por último, detallamos las conclusiones y las implicaciones didácticas que se derivan de nuestro trabajo.

\section{ANTECEDENTES TEÓRICOS Y MODELOS USADOS PARA CALIFICAR Y CLASIFICAR LAS NARRACIONES INFANTILES}

Para el presente estudio nos hemos basado en distintos modelos de análisis y clasificaciones que, a pesar de ciertas limitaciones que advertimos en ellos -y que más adelante detallaremos-, nos han servido para describir de forma nítida las características identificadas en las narraciones que constituyen nuestro objeto de análisis. Podremos de este modo postular un modelo alternativo de evaluación de la estructura narrativa que mejor se adapte al corpus trabajado.

\subsection{Las estructuras de las narraciones de Applebee}

Las investigaciones realizadas por Arthur Applebee (1978) indican dos procesos básicos para la estructuración narrativa: centrado y encadenamiento, que son, según él, los principales constituyentes de la formación de historias. Las estructuras narrativas que son capaces de controlar los niños a estas edades fueron identificadas por este mismo autor en su libro The Child's Concept of Story (1978), a través de seis formas básicas que pueden relacionarse con los estadios de desarrollo propuestos por Vygotski (1981), mostrando un mismo orden en el desarrollo general. 
Figura 1. Estructuras narrativas según Applebee

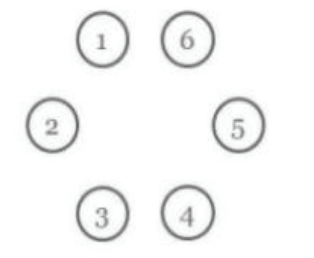

A. Apilamiento (Heaps)

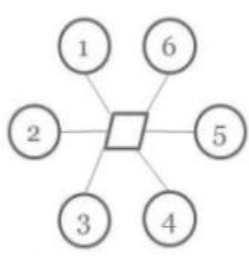

B. Núcleo compartido (Sequences)

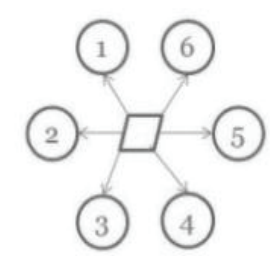

C. Núcleo focalizado (Primitive Narratives)

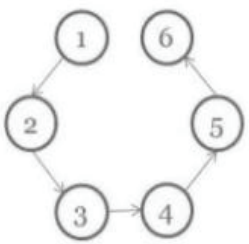

D. Episodios cambiantes (Unfocused Chains)

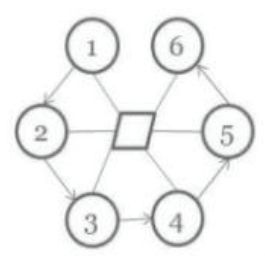

E. Cadena focalizada (Focused Chains)

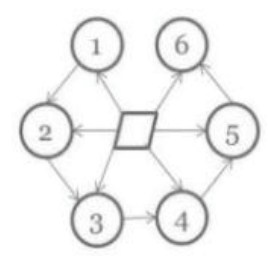

F. Narración completa (Narratives)

Fuente: Applebee, 1978: 58.

Seguidamente, especificamos las características principales de cada una de las estructuras, determinando a qué edades aproximadas suele aparecer cada tipología; pero es importante tener en cuenta que, aunque los modos de organización surgen de forma clara, muchas de las historias que nos llegan a contar los niños pueden utilizar más de una de las formas de organización en el curso de su narración (Applebee, 1978: 57-66):

A. Apilamiento (Heaps). A los 2 años de edad:

- Nombra y describe a través de una lista enumerativa de acciones y personajes sin presentar un tema central en la narración.

- La organización está basada en la percepción inmediata, con escasos vínculos entre una frase y otra.

B. Núcleo compartido (Sequences). Entre los 2 y los 4 años de edad: 
- Describe sucesos alrededor de un núcleo temático, relacionados entre sí por una característica compartida con el núcleo de la historia.

- Estos eventos están vinculados de forma superficial y arbitraria, sin relación causal o temporal entre ellos -no hay trama-.

C. Núcleo focalizado (Primitive Narratives). Hacia los 3-4 años de edad:

- Núcleo central definido, de cierta importancia para el niño, alrededor del que se reúnen eventos y atributos, asociados no por similitud, sino por complementariedad.

- La colección de sucesos o atributos reunidos aclara y amplifica el núcleo inicial, pero no hay un desarrollo propiamente dicho.

D. Episodios cambiantes (Unfocused Chains). Entre 4 y 5 años de edad:

- Se encadenan incidentes con un vínculo lógico o causal entre ellos, pero sin un núcleo ni una dirección definida en la historia.

- Existe una estructura narrativa -inicio, desarrollo y final-.

- Falta definición en el ajuste de la historia - personajes que entran y salen del cuento, cambios de acción repentinos, etc. - .

E. Cadena focalizada (Focused Chains). Alrededor de los 5 años:

- Procesos de encadenamiento y de centrado en torno a unos atributos concretos que van integrándose dentro de la narración.

- Hay un personaje como centro de la narración, que protagoniza una serie de acontecimientos ligados unos con otros como en el estadio anterior.

F. Narración completa (Narratives). Alrededor de los 5 y 6 años:

- La narración posee un tema central, personajes y trama, desarrollada lógica y cronológicamente.

- Presenta un final como resolución al problema planteado en el inicio de la historia. El núcleo central se desarrolla a lo largo del curso del relato, pues cada incidente elabora un aspecto nuevo de ese tema.

- Hay atisbos de una temática moral.

\subsection{La escala de desarrollo narrativo de Landaeta-Coloma-Pavez}

De forma similar al modelo de Applebee, este análisis se basa en criterios estructurales, aunque su objetivo no es clasificar las narraciones, sino calificar mediante puntuación la mayor o menor estructuración de los relatos contados por los niños. Así pues, se distingue entre: relatos no estructurados, los que no presentan categorías básicas del discurso narrativo; y relatos estructurados, los que evidencian una estructuración narrativa más definida (Landaeta et al., 2009). En este caso, para el análisis de los relatos, las investigadoras confeccionaron una escala de desarrollo narrativo con los indicadores que caracterizan las narraciones no estructuradas, la transición hacia la siguiente etapa y, finalmente las narraciones estructuradas. 
Figura 2. Escala de desarrollo narrativo según Landaeta-Coloma-Pavez

\begin{tabular}{|c|c|c|c|c|}
\hline & $\begin{array}{l}\text { NIVEL DE } \\
\text { DESEMPEÑO } \\
\text { NARRATIVO }\end{array}$ & CARACTERÍSTICAS & EDAD \\
\hline \multirow{4}{*}{\multicolumn{2}{|c|}{ NO ESTRUCTURA }} & 1 & NO DICE NADA & \multirow{3}{*}{3 AÑOS } \\
\hline & & 2 & DICE SOLO UNA ORACIÓN & \\
\hline & & 3 & $\begin{array}{l}\text { AGLUTINA SECUENCIAS DE ACCIONES } \\
\text { Y/O ESTADOS }\end{array}$ & \\
\hline & & 4 & $\begin{array}{l}\text { AGRUPA ENUMERATIVAMENTE } \\
\text { EN TORNO A UN PERSONAJE }\end{array}$ & \\
\hline \multirow{2}{*}{\multicolumn{2}{|c|}{ TRANSICIÓN }} & 5 & $\begin{array}{c}\text { HACE SECUENCIAS: } \\
\text { ACCIÓN + OBSTÁCULO Y/O } \\
\text { OBSTÁCULO + RESULTADO }\end{array}$ & \\
\hline & & 6 & $\begin{array}{l}\text { PRESENTACIÓN Y EPISODIO: } \\
\text { AMBOS INCOMPLETOS }\end{array}$ & \\
\hline \multirow{2}{*}{\multicolumn{2}{|c|}{\begin{tabular}{l|l} 
I. RELATA CON \\
PRESENTACION \\
Y EPISODIO, \\
SOLO UNO DE \\
ELLOS \\
COMPLETO
\end{tabular}}} & 7 & $\begin{array}{l}\text { PRESENTACIÓN COMPLETA } \\
\text { Y EPISODIO INCOMPLETO }\end{array}$ & \multirow{3}{*}{4 AÑOS } \\
\hline & & 8 & $\begin{array}{l}\text { PRESENTACIÓN INCOMPLETA } \\
\text { Y EPISODIO COMPLETO }\end{array}$ & \\
\hline \multirow{2}{*}{\multicolumn{2}{|c|}{\begin{tabular}{l|l} 
S & II. RELATA CON \\
T & PRESENTACIÓN \\
R & COMPLETA+ \\
U & EPISODIO \\
U & COMPLETO, \\
C & PERO SIN FINAL \\
\end{tabular}}} & 9 & $\begin{array}{l}\text { PRESENTACIÓN Y EPISODIO: } \\
\text { AMBOS COMPLETOS } \\
\text { (SIN FINAL) }\end{array}$ & \\
\hline & & 10 & $\begin{array}{l}\text { PRESENTACIÓN COMPLETA } \\
\text { CON ATRIBUTO Y EPISODIO } \\
\text { COMPLETO (SIN FINAL) }\end{array}$ & \multirow{3}{*}{5 Y 6 AÑOS } \\
\hline $\begin{array}{l}\mathrm{T} \\
\mathrm{U} \\
\mathrm{R} \\
\mathrm{A}\end{array}$ & \multirow{3}{*}{$\begin{array}{l}\text { III. RELATA CON } \\
\text { PRESENTACION } \\
\text { COMPLETA, } \\
\text { EPISODIO } \\
\text { COMPLETO } Y \\
\text { FINAL }\end{array}$} & 11 & $\begin{array}{c}\text { PRESENTACIÓN Y EPISODIO: } \\
\text { AMBOS COMPLETOS } \\
\text { MÁS FINAL }\end{array}$ & \\
\hline & & 12 & $\begin{array}{l}\text { PRESENTACIÓN COMPLETA } \\
\text { CON ATRIBUTO } \\
\text { ESPISODIO COMPLETO Y FINAL }\end{array}$ & \\
\hline & & 13 & $\begin{array}{c}\text { PRESENTACIÓN COMPLETA } \\
\text { CON ATRIBUTO } \\
\text { ESPISODIO COMPLETO CON META Y FINAL }\end{array}$ & 10 AÑOS \\
\hline
\end{tabular}

Fuente: Landaeta, M. et al., 2009: 382.

\subsection{El esquema de puntuación narrativa (narrative scoring scheme) de} Heilmann-Miller-Nockerts

El modelo de análisis de estos autores es el resultado de la crítica a los esquemas de Reilly et al. (2004), Applebee (1978) y Stein (1988), una vez aplicados a su corpus de re-narraciones (retells) infantiles. Su propuesta, según explican (Heilmann, Miller y Nockerts, 2010), evita el sesgo hacia los valores superiores que se producía al analizar sus textos con las demás escalas, normalizando esos resultados en virtud del análisis de múltiples parámetros y 
factores implícitos en la estructura narrativa. Así, su esquema consiste en la puntuación entre 0 y 5 de estos siete apartados, sumando una puntuación final de 0 a 35:

1. Introducción: elaboración menor o mayor de la ambientación espaciotemporal y la presentación de personajes.

2. Desarrollo de los personajes: desde la mención inconsistente de los personajes o la omisión de algunos de ellos, hasta la distinción controlada de personajes principales y secundarios, y el uso del estilo directo en los diálogos.

3. Estados mentales: se mide el uso mayor o menor de palabras que describan rasgos psicológicos de los personajes.

4. Referencias: valoración de la referencialidad controlada de los pronombres y sus antecedentes gramaticales.

5. Resolución del conflicto: mide desde la ausencia de mención del conflicto, hasta su resolución lograda en forma de pasos en la trama.

6. Cohesión: se valora aquí el orden lógico de los sucesos y la fluidez de sus transiciones.

7. Conclusión: desde la interrupción brusca del relato hasta la finalización de la trama y el uso de fórmulas discursivas de cierre.

\subsection{Complejidad y organización narrativa desde la perspectiva de los géneros (Shiro)}

Según Shiro (2011), el género discursivo resulta necesario para comprender las distintas situaciones comunicativas. El dominio gradual de los géneros discursivos facilita el acceso a diferentes grupos sociales y comunidades. Por otra parte, el género determina la organización textual y refleja la complejidad narrativa, de la que hemos hablado anteriormente -organización y estructuración-, añadiendo en este caso el propósito comunicativo.

Siguiendo las aportaciones hechas por Shiro (2011), encontramos dos aproximaciones sobre el estudio del desarrollo del género narrativo que, aplicadas a los relatos infantiles, proporcionan una visión más ponderada de sus diferentes producciones:

- Definición del género de acuerdo con las fuentes de conocimiento que dan origen a la narración: este enfoque determina la manera en que se organiza la experiencia para ser integrada en el discurso. Hudson y Shapiro (1991) describieron tres géneros narrativos:

- Guiones: un primer estadio en el que el niño tendría una representación general de los eventos. La información esencial se basa en lo que sucede de forma usual al narrador, experiencias cotidianas que se desarrollan habitualmente.

- Relatos personales: segundo estadio en el que se desarrollan en el niño habilidades para referirse a eventos excepcionales sobre sus 
experiencias personales. La información primordial se refiere a situaciones y eventos que han sucedido una sola vez.

- Relatos de ficción: tercer estadio caracterizado por una estructura más compleja, con episodios que destacan estados internos y motivaciones, tanto de personajes como de la persona que narra.

- Distinción entre género narrativo desde el punto de vista de la interacción. Heath (1986) postulaba cuatro tipos universales de narración:

- Transmisiones: "repeticiones verbales o explicaciones de escenas de actividad que o bien reciben la atención de quienes participan en el reporte o son planificadas para el futuro" (Heath, 1986: 88). No se dan de forma voluntaria, sino que se sugieren por parte de una figura de autoridad.

- Relatos: producciones narrativas sobre experiencias pasadas seleccionadas de forma voluntaria por el narrador, que decide compartir con los oyentes.

- Recuentos: verbalización de experiencias pasadas que son compartidas con el interlocutor y evocadas por éste.

- Cuentos: relatos que son tomados por los oyentes como fantásticos o irreales, en los que interviene la imaginación de la persona que narra.

Por otra parte, Peterson y McCabe (1983) observaron distintas etapas evolutivas a la hora organizar los relatos personales, que pueden confrontarse con los estadios de Applebee:

- Eventos generales: guion de eventos típicos que no se refieren a un pasado específico.

- Eventos mínimos: eventos que se repiten dentro de una narración, sin conducir a un punto culminante.

- Patrón cronológico: secuencias cronológicas simplificadas de los eventos, sin que estos se encuentren vinculados causal o temporalmente. No existe punto culminante.

- Eventos saltados: los eventos que no siguen secuencias graduales que conduzcan al punto culminante.

- Final en el punto culminante: narraciones en las que se echa en falta resolución al conflicto planteado.

- Patrón clásico: narración que contiene, de forma obligatoria, componentes de orientación, complicación, punto culminante y resolución. Puede contener resumen y coda.

Según estos mismos autores, para la franja de edad que nos ocupa el presente estudio, se sugiere el patrón de eventos generales, siendo de forma gradual el proceso de desarrollo de habilidades hasta llegar a producir narraciones con un patrón clásico. 


\subsection{Discusión de los modelos}

De forma análoga a lo que les sucedió a Heilmann et al. (2010), estos modelos de análisis se han demostrado, de un modo u otro, parcialmente deficientes a la hora de cuantificar con fidelidad la complejidad mayor o menor de las narraciones infantiles del corpus que habíamos recogido. Sin duda, como decíamos al principio del apartado, cada uno de estos modelos aporta una perspectiva sumamente interesante, que hemos intentado aprovechar. Pero ninguno nos ha resultado plenamente satisfactorio, tal y como se detalla en el apartado 3.4 del presente artículo.

Nos parece claro que los modelos multifactoriales dan cuenta más cabal de las variadas dimensiones que las estructuras narrativas poseen. Así, el esquema de Heilmann-Miller-Nockerts, al contemplar aspectos como la coherencia pronominal, la descripción psicológica de los personajes o el uso de fórmulas discursivas de cierre, entre otros, pasa a considerar una casuística mayor que la de otros modelos como los de Applebee o Landaeta-Coloma-Pavez, centrados únicamente en la relación estructural entre las secuencias narradas. Aun así, existen, a nuestro juicio, otros factores intrínsecos a la estructura narrativa que aún no se han mencionado, y que se revelaron de cierta importancia para la diferenciación de los cuentos infantiles de nuestro corpus. Tal vez esto se deba a la diferente metodología en la recogida de las muestras -en Heilmann et al., por ejemplo, se trataba de narraciones de un cuento de Marcer Meyer que habían escuchado antes los niñoso a sus propósitos -Landaeta et al. pretendían estudiar el Trastorno Específico del Lenguaje-.

Por otro lado, la ventaja que ofrecen los modelos de Applebee y Shiro frente a los otros está en que no se limitan a calificar las producciones narrativas de los niños, sino que también las clasifican en estadios de desarrollo de su capacidad narrativa. Estos esquemas de categorías nos parecen globalmente un acierto, aunque la descripción de cada una de ellas -a través de factores e indicadores de complejidad narrativa- nos parece incompleta; además, para la franja de edad que trabajamos en nuestra muestra -3-4 años- podría detallarse aún más.

\section{NUESTRO CORPUS}

\subsection{Objetivo, población y muestra}

El objetivo al que nos hemos dirigido con la recogida y análisis de narrativas infantiles ha sido, como se ha mencionado ya, la elaboración de un modelo de calificación y clasificación de las estructuras de estos relatos que fuera descriptivo de la totalidad de factores que conforman dichas narraciones. Para el estudio se empleó como muestra un grupo de niños de un aula del primer curso de Educación Infantil, de la escuela Jaume I de La Sénia -Tarragona-. El grupo estuvo formado por 9 niñas y 9 niños de entre tres y cuatro años de edad. Nos encontramos con distintas nacionalidades dentro del grupo: 1 niño de Argelia y 2 de Rumanía, el 
resto son de nacionalidad española. La mayoría provienen de familias con niveles socioeconómicos de clase media.

\subsection{Metodología de experimentación en el aula}

Durante los meses de marzo y abril de 2013, se realizó un estudio experimental sobre habilidades narrativas y creativas a los 3-4 años de edad. Dentro de esta experimentación, una de las pruebas que se establecieron nos permitió obtener distintas informaciones sobre la habilidad narrativa de los niños y nos permitió clasificar las narraciones según los modelos estructurales definidos en los antecedentes teóricos. Utilizando como base la propuesta "Cuéntame un cuento" basado en Pitcher y Prelinger, 1963-, se pidió individualmente a cada uno de los niños, que nos contaran un cuento de forma no dirigida y abierta.

Se dio por hecho que, dentro de la dinámica y del conjunto de la prueba, todos los niños de la muestra sabían qué significaba "contar un cuento" y qué se entiende por "cuento", puesto que habían recibido suficiente input al respecto en forma de modelos contados por las maestras en el aula, en las sucesivas fases del experimento.

Al inicio de la prueba, se explicó a los niños el funcionamiento de la misma y unas mínimas normas a seguir para realizar la prueba con éxito. En todos los casos, la petición inicial fue idéntica: "-Nombre-, cuéntame un cuento". Durante el desarrollo, se intentó intervenir de la forma menos injerente posible a través de preguntas muy generalistas: ¿Y después?, ¿Y entonces?, ¿Qué ocurrió?, ¿Qué pudo pasar?, ¿Y qué más?, ¿Ya?, ¿Acaba así?, ¿Cómo termina?, etc. Se intervino cuando hizo falta, con entonaciones atractivas y refuerzos positivos para animar a los niños a contar, intentando influir lo mínimo posible en el experimento para garantizar unos resultados fiables.

Con posterioridad advertimos un aspecto que podría haberse mejorado: la posición para contar. Los niños permanecían sentados mientras inventaban y narraban el cuento, puesto que ello facilitaba el registro audiovisual; sin embargo, consideramos que tal vez los resultados habrían sido diferentes si se les hubiera dado libertad para moverse por la sala, de acuerdo con algunas insinuaciones clásicas de creación literaria infantil -Chukovsky 1971: 65: "el niño necesita estar en movimiento, al menos con las manos o los pies, cuando compone sus canciones"; Rodari 1973: 226: "[la dramatización supone] una lectura del juego como narración de actos" -.

Otro aspecto que hay que considerar es el espacio en el que se realizaron las pruebas y los elementos que allí había. Esta circunstancia condicionó la creación narrativa. Es fácil suponer que si hubiéramos cambiado de sala, los personajes y temas en las narraciones hubiesen sido distintos. 


\subsection{Técnicas de recogida de datos y su análisis}

La totalidad de las pruebas realizadas se registraron a través de grabaciones audiovisuales, obteniendo un total de 22 horas de registro. Una vez recogidas todas las grabaciones, nos dispusimos a la transcripción y traducción de todas las historias contadas por los niños - la mayoría de los niños utilizaba la lengua catalana-. Esta técnica de recogida de datos, junto con la observación -participante y no participante- fue de gran ayuda, e instrumento principal, para la extracción de información y posterior análisis detallado de cada uno de los cuentos contados.

$\mathrm{El}$ análisis de cada una de estas narraciones, aplicando los diferentes esquemas de calificación y clasificación de estructuras narrativas referidos en el apartado 2, se llevó a cabo mediante el sistema de "doble ciego". En primer lugar, cada uno de los autores de este artículo analizó por su parte los relatos de los niños, y los puntuó y clasificó. Después, se pusieron en común estos análisis y se debatieron las divergencias en su puntuación -cuando las había-, para concluir y ajustar un resultado consensuado.

\subsection{Aplicación de los modelos de análisis narrativo sobre nuestro corpus}

A continuación, ofrecemos los datos y las tablas resultantes de la aplicación de los modelos explicados en el apartado 2 a nuestro propio corpus, con el fin de detallar sus diferencias.

\subsubsection{Estructuras de las narraciones infantiles: Applebee}

Utilizamos un sencillo método de puntuación, siendo 1 la puntuación mínima estructura A- y 6 la máxima -estructura F-. Nos vimos obligados a utilizar decimales -p. e. 2.5-, puesto que algunos de los relatos se encontraban en fase de transición entre una estructura y otra. No se puntuaron los casos en los que los niños no dijeron nada, y algún caso en el que se mostraba confusión respecto al género, sin obtener una narración, sino una canción. Mostramos la Tabla 1 con las puntuaciones obtenidas en cada uno de los relatos:

Tabla 1. Puntuación en el modelo estructuras Applebee

\begin{tabular}{|c|c|c|c|}
\hline & Edad & Cuento 1 & Cuento 2 \\
\hline $\operatorname{Ad} \widehat{\sigma}$ & $3 ; 4$ & 1 & 1 \\
\hline $\operatorname{Adr} \sigma^{\lambda}$ & $3 ; 9$ & 3.5 & 3.5 \\
\hline $\mathbf{A} \mathbf{i} q$ & $4 ; 2$ & 3 & 2 \\
\hline $\mathbf{C a}$ ? & 4 & 0 & 1 \\
\hline $\mathbf{C l} q$ & $3 ; 11$ & 2 & 3 \\
\hline $\mathbf{E i}+$ & $3 ; 4$ & 1 & 2 \\
\hline El $q$ & $3 ; 5$ & 2 & 3 \\
\hline Gu ${ }^{\lambda}$ & $4 ; 1$ & 2 & 3 \\
\hline Ia $\hat{O}$ & $3 ; 4$ & 1 & 1 \\
\hline
\end{tabular}




\begin{tabular}{|c|c|c|c|}
\hline Jo $\stackrel{\lambda}{\circ}$ & $3 ; 6$ & 3 & 0 \\
\hline $\mathbf{J u} \propto$ & $3 ; 10$ & 3 & 1 \\
\hline $\mathbf{K e}{ }^{\hat{N}}$ & $3 ; 4$ & 4 & 4 \\
\hline $\mathbf{L a} P$ & $3 ; 8$ & 0 & 2 \\
\hline Ma ${ }^{\lambda}$ & $3 ; 10$ & 1 & 1 \\
\hline $\mathbf{M e}$ ㅇ & $3 ; 5$ & 3.5 & 3.5 \\
\hline $\operatorname{Ra}{ }^{\lambda}$ & $3 ; 7$ & 1.5 & 2 \\
\hline RA $\sigma^{\lambda}$ & $4 ; 2$ & 0 & 0 \\
\hline Ya $P$ & $3 ; 8$ & 1.5 & 2 \\
\hline
\end{tabular}

Si comparamos los resultados obtenidos en nuestro estudio con los obtenidos por Applebee -Figura 3-, en la misma franja de edad, observamos ligeras diferencias respecto al tipo de estructuras obtenidas. Por una parte, Applebee identifica estructuras del tipo $\mathrm{F}$-narración completa- en los relatos obtenidos y, en un número más alto, la $\mathrm{E}$-cadena focalizada-. En nuestro estudio, no hemos identificado dichas estructuras en ninguna de las narraciones hechas por parte de los niños de 3-4 años, siendo la $\mathrm{C}$-núcleo focalizado- la más frecuente. Se ha observado en muchas de las narraciones un núcleo central definido al que se le otorga gran importancia dentro del relato, presentando cierta estructura narrativa, aunque no muy elaborada. Por otra parte, son más las narraciones identificadas en nuestro estudio con una estructura A -apilamiento-, observando una organización narrativa perceptiva, muy primitiva y sin un tema central definido. Lo mismo sucede con la estructura del tipo D -episodios cambiantes-, identificada en más ocasiones que en el estudio hecho por Applebee.

Figura 3. Comparación de los resultados obtenidos, con los de Applebee, a los 3 años

\begin{tabular}{|r|r|r|r|r|}
\hline $100 \%$ & & & \\
$80 \%$ \\
$60 \%$
\end{tabular}




\subsubsection{Aplicación del modelo de Landaeta-Coloma-Pavez}

Puntuamos de forma progresiva, siendo 1 la mínima puntuación y 13 la máxima. Mostramos a continuación las puntuaciones obtenidas en cada uno de los relatos:

Tabla 2. Puntuación escala de desarrollo narrativo

\section{Edad Cuento $1 \quad$ Cuento 2}

\begin{tabular}{|c|c|c|c|}
\hline Ad $\widehat{\sigma}$ & $3 ; 4$ & 3 & 3 \\
\hline Adr ${ }^{\lambda}$ & $3 ; 9$ & 8 & 11 \\
\hline $\mathbf{A i}+9$ & $4 ; 2$ & 5 & 4 \\
\hline $\mathbf{C a}+$ & 4 & 1 & 3 \\
\hline $\mathbf{C l}$ 웅 & $3 ; 11$ & 5 & 4 \\
\hline $\mathbf{E i}+\stackrel{\rho}{1}$ & $3 ; 4$ & 4 & 5 \\
\hline El $\stackrel{\circ}{1}$ & $3 ; 5$ & 3 & 11 \\
\hline Gu ${ }^{\lambda}$ & $4 ; 1$ & 4 & 5 \\
\hline Ia ${ }^{\lambda}$ & $3 ; 4$ & 3 & 2 \\
\hline Jo ${ }^{\lambda}$ & $3 ; 6$ & 2 & 2 \\
\hline $\mathbf{J u} \stackrel{\circ}{ }$ & $3 ; 10$ & 3 & 2 \\
\hline Ke ${ }^{\hat{O}}$ & $3 ; 4$ & 8 & 8 \\
\hline La ㅇ & $3 ; 8$ & 1 & 4 \\
\hline Ma $\hat{~}$ & $3 ; 10$ & 3 & 3 \\
\hline Me + & $3 ; 5$ & 9 & 9 \\
\hline $\operatorname{Ra}{ }^{\lambda}$ & $3 ; 7$ & 4 & 4 \\
\hline RA ${ }^{\lambda}$ & $4 ; 2$ & 1 & 1 \\
\hline $\mathbf{Y a}+$ & $3 ; 8$ & 4 & 5 \\
\hline
\end{tabular}

$\mathrm{Si}$ analizamos los resultados obtenidos -Figura 4-, observamos como predominan con un porcentaje igual $-23 \%$ del total de narraciones en cada casolos relatos en los que los niños aglutinan secuencias de acciones y/o estados puntuación 3- junto con los que agrupan de forma enumerativa acciones en torno a un personaje -puntuación 4-. Esto demuestra cómo a los 3-4 años de edad los niños muestran, en general, un nivel de desempeño narrativo no estructurado.

Por otra parte nos encontramos con un $6 \%$ de relatos que ofrecen presentación y episodio completos más final -puntuación 11-. En este caso se trataría de narraciones completamente estructuradas. 
Figura 4. Resultados modelo Landaeta-Coloma-Pave

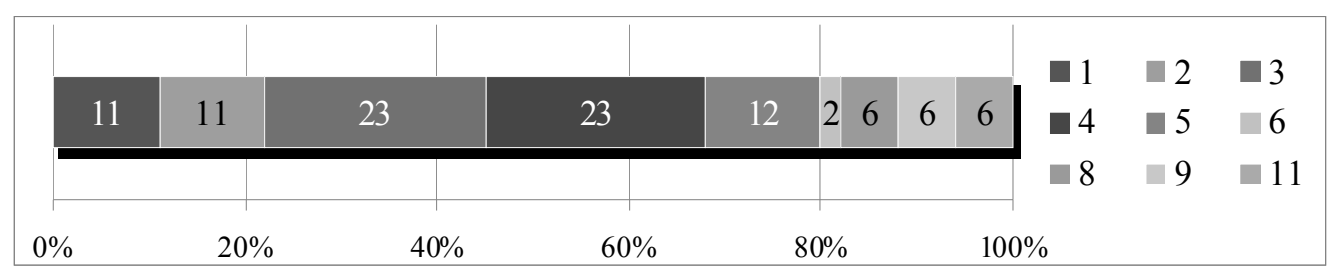

\subsubsection{Aplicación del modelo de Heilmann-Miller-Nockerts}

Utilizamos el mismo sistema de puntuación ofrecido por estos autores, siendo entre 0 y 5 por cada uno de los siete apartados mencionados en los antecedentes teóricos, sumando finalmente una puntuación de 0 a 35. Mostramos a continuación las puntuaciones obtenidas en cada uno de los relatos:

Tabla 3. Calificación esquema de puntuación narrativa

\begin{tabular}{|c|c|c|c|}
\hline & Edad & Cuento 1 & Cuento 2 \\
\hline $\operatorname{Ad} \sigma^{\lambda}$ & $3 ; 4$ & 7 & 8 \\
\hline $\operatorname{Adr} \sigma^{\lambda}$ & $3 ; 9$ & 20 & 19 \\
\hline $\mathbf{A i} \stackrel{\circ}{\circ}$ & $4 ; 2$ & 14 & 11 \\
\hline Ca + & 4 & 0 & 8 \\
\hline Cl 9 & $3 ; 11$ & 18 & 13 \\
\hline $\mathbf{E i}$ 우 & $3 ; 4$ & 8 & 17 \\
\hline El 운 & $3 ; 5$ & 12 & 19 \\
\hline Gu $\hat{\sigma}$ & $4 ; 1$ & 14 & 15 \\
\hline Ia $\sigma^{\lambda}$ & $3 ; 4$ & 8 & 9 \\
\hline Jo $\widehat{\sigma}$ & $3 ; 6$ & 13 & 0 \\
\hline $\mathbf{J u} q$ & $3 ; 10$ & 9 & 9 \\
\hline Ke ${ }^{\hat{~}}$ & $3 ; 4$ & 17 & 19 \\
\hline La 9 & $3 ; 8$ & 0 & 12 \\
\hline Ma ${ }^{\lambda}$ & $3 ; 10$ & 8 & 13 \\
\hline Me $\stackrel{+}{+}$ & $3 ; 5$ & 18 & 21 \\
\hline $\operatorname{Ra}{ }^{\lambda}$ & $3 ; 7$ & 11 & 13 \\
\hline RA & $4 ; 2$ & 0 & 0 \\
\hline Ya $\odot$ & $3 ; 8$ & 14 & 16 \\
\hline
\end{tabular}

Este modelo, como puede verse, ofrece una mayor dispersión de los resultados, al ser mayor su rango de puntuación -lo analizaremos de forma estadística más adelante-. Esto permite afinar más en los detalles que diferencian unos relatos y otros de los niños. Así, mientras que en el modelo anterior, por ejemplo, los 
cuentos 1 y 2 de Ke se puntuaban con un 8, usando el modelo de Heilmann podemos afirmar que existe una sutil diferencia entre esas dos producciones narrativas: la que va de 17 a 19. Algo análogo ocurre con el caso de Me y otros.

\section{ANÁLISIS DE RELATOS INFANTILES}

\subsection{Operacionalización de conceptos}

Con el fin de concretar en todas sus dimensiones el concepto genérico de "habilidad narrativa", se operacionalizó en una serie de factores, que a su vez se dividieron en un racimo de indicadores. La presencia de unos $u$ otros indicadores variables- en los relatos infantiles analizados, revela así un grado mayor o menor de desarrollo de esa dimensión de la habilidad narrativa del narrador.

Así, de forma simultánea al análisis del corpus, y partiendo de la base de los modelos teóricos precedentes, fuimos estableciendo y consensuando la siguiente lista de factores operativos:

1. Comprensión y control del género narrativo

2. Ficcionalización

3. Complejidad

4. Coherencia

5. Cohesión

6. Habilidad discursiva y pragmática

7. Soltura

\subsection{Indicadores}

Los 7 factores citados pudieron concretarse en indicadores específicos para objetivar el análisis de los textos, según explicamos a continuación.

\subsubsection{Comprensión y control del género narrativo}

En el corpus recogido hallamos producciones infantiles que distaban de poder ser consideradas propiamente relatos, tales como retahílas, descripciones o enumeraciones de objetos. Esto revela un distinto conocimiento de la noción de "cuento" por parte de los niños, que es prelativo en relación con casi todos los demás factores. Igualmente, la producción de un solo relato o bien de varios "minirelatos" aislados nos pareció relevante en este aspecto, así como la inclusión o no de fórmulas de inicio o final y de un título.

Con todo ello, pues, encontramos en el corpus cuentos con muy escaso control de la narración:

La mama meua té una nina. I un piano. I a Mickey. I un oso. Una vegada la mama meua un monte. Un piano. Una vaca. Muuuu. Un piano [...] Una vegada... Un cuento, un Mickey. Pos aquí hi ha los números 1. Un cuento de 
Mickey. I una lluna. [...] “Patim, patam, y Patufet, patim, patum”. (Ad núm. $1)^{1}$

Frente a otros mucho más controlados:

Rayo McQueen corre, i Francesco corre. Que Rayo està guanyant. Que Rayo ha perdut la carrera. Que tenia que canviar les rodes pero no podrá canviar les rodes, que solo, solo podrá... que a Rayo McQueen vull que li fiquen gasolina, però no podrá canviar les rodes. Que Rayo ya ha perdut la carrera, ya. I el conte ja s'ha acabat. (Ke núm. 2$)^{2}$

\subsubsection{Ficcionalización}

El grado en que los niños se distancian de su propia experiencia cotidiana en los relatos que inventan marca, a nuestro juicio, una diferencia cualitativa. Así, dentro del corpus recogido se pueden encontrar relatos muy basados en las propias experiencias vitales -recuerdos de anécdotas, detalles de eventos sucedidos anteriormente, etc.-, frente a otros distanciados, con la inclusión de personajes ficticios y todo tipo de peripecias imaginativas. Como es lógico, existe toda una gradación de tipos intermedios entre un polo y otro, incluyendo las variaciones sobre secuencias de cuentos y películas, y recuerdos de narraciones escuchadas aspecto al que pensamos dedicar un nuevo artículo próximamente-.

Un ejemplo del extremo vivencial sería este:

Jo un dia, a la piscina, quan estàvem al càmping, me vaig, vaig jugar en la pilota $i$ en lo xurro $i$ en Joan. I jo un dia quan vaig anar a un, quan vaig anar que jo m'afonava a una piscina, me vaig afonar a buscar els cotxes en les ulleres, perquè los cotxes, los cotxes los fiquem a dins de l'aigua i los trobem per dins la piscina. (Ai núm. 1)

\footnotetext{
${ }^{1}$ Mi mamá tiene una muñeca. Y un piano Y a Mickey. Y un oso. Una vez la mamá mía un monte. Un piano. Una vaca. Muuuu. Un piano [...] Una vez... Un cuento, un Mickey. Pues aquí hay los números 1 . Un cuento de Mickey. Y una luna. [...] "Patim, patam, y Patufet, patim, patum".

${ }^{2}$ Rayo McQueen corre, y Francesco corre. Que Rayo está ganando. Que Rayo ha perdido la carrera. Que tenía que cambiar las ruedas pero no podrá cambiar las ruedas, que sólo, sólo podrá... que a Rayo McQueen quiero que le pongan gasolina, pero no podrá cambiar las ruedas. Que Rayo ya ha perdido la carrera, ya. Y el cuento ya se ha terminado.

${ }^{3}$ Yo un día, a la piscina cuando estábamos al camping, me fui, jugué con la pelota y con el churro y con Joan. Y yo un día cuando fui a un, cuando fui que yo me hundía a una piscina, me hundí a buscar los coches con las gafas, porque los coches, los coches los ponemos dentro del agua y los encontramos por dentro la piscina.
} 
Mientras que este otro resulta netamente ficcional:

Que un caballito se iba a buscar una cesta. Y después, después iba pel bosc i va encontrar un llop. Pero después va anar a... después va anar a encontrar un bebé de juguete. Que después va encontrar una floreta. Que va encontrar un Piolín. Que después encontraba números, como aquella: 1, 2, 3, 4, 5, 6, 7, $8,9 \ldots$ Que después encontraba un tomate y un helicóptero. El llop. Y també va encontrar lo caballito. Y después va encontrar una araña, jay! como aquella (señala los dibujos de la pared). Y después andaba por aquí y se la va entrar aquí (se señala la rodilla). Que, que era, le va entrar, le va entrar a, a... al llop. Que después va anar a encontrar números. Y ya está. $(\mathrm{Cl} \text { núm. } 2)^{4}$

\subsubsection{Complejidad}

Una variable que, sorprendentemente, obviaban los análisis teóricos precedentes, era la longitud de las narraciones infantiles. Pensamos, sin embargo, que el mero análisis cuantitativo del número de palabras de sus producciones ya arroja cierta luz sobre la destreza narrativa del niño en cuestión, e incluso la mayoría de las veces sobre la complejidad estructural del relato. Otros indicadores, como el número de personajes implicados, los detalles aportados a la descripción de los mismos y de la ambientación, así como la existencia o no de líneas secundarias en la trama, completan este factor de análisis de la complejidad de estos relatos. Hay que señalar que dicha complejidad no siempre es sinónima de narración eficaz -en muchas ocasiones les conduce a la confusión-, pero al menos sí revela un intento de desarrollar argumentos más elaborados y precisos.

En consonancia con esto, en nuestro corpus existen relatos muy poco complejos:

Del caball. El menut i el gran se’n van anar. Estan allí els caballs. No sé. (Jo núm. 1$)^{5}$

Frente a otros que lo son más:

\footnotetext{
${ }^{4}$ Que un caballito se iba a buscar una cesta. Y después, después iba por el bosque y encontró un lobo. Pero después fue a... después fue a encontrar un bebé de juguete. Que después encontró una floreta. Que encontró un Piolín. Que después encontraba números, como aquella: 1, 2, 3, 4, 5, 6, 7, 8, 9... Que después encontraba un tomate y un helicóptero. El lobo. Y també encontró lo caballito. Y después encontró una araña, ¡ay! como aquella. Y después andaba por aquí y se le entró aquí. Que, que era, le entró, le entró a, a... al lobo. Que después fue a encontrar números. Y ya está.

${ }^{5}$ Del caballo. El pequeño y el grande se marcharon. Están allí los caballos. No sé.
} 
Que surtia una aranya que era molt menudeta i era roja. Pos jo vaig tocar una de color roig a los columpios, pero no, pero no vaig plorar perque l'aranya tenia les potes de color taronja. Pero a mí no m'agrada l'aranya de color roig. Jo la volia matar. Que jo, jo... que jo no la vaig matar. Que va sortir un cuc i se va minjar l'aranya. Que va sortir una zebra i se'n va anar en lo cuc. I va sortir un calamar i va trobar un oso i se'n va anar en lo oso i van minjar en lo calamar un kiwi. Que sortiria una vaca que ponia llet damunt de la zebra blanca i negra. [...] Que sortia una maduixa i un cuc se va minjar la maduixa i l'aranya també. Que va sortir una maduixa i el oso també se va minjar la maduixa i la zebra també. I allavontes l'aranya se va minjar a la zebra i la zebra estava "morida". Que l'arana també se minjava les cames i les orelles, i també la coa i lo cul. (E1 núm. 2)

\subsubsection{Coherencia}

Hay muchas formas de medir la coherencia de un relato. Dentro de las características manifestadas en los cuentos inventados por los niños de esta edad, el indicador más eficiente tal vez sea el seguimiento de una lógica -o crono-lógicaen los eventos, sumado a la existencia o no de transiciones fluidas entre las diferentes secuencias, y la resolución de los conflictos planteados $-\mathrm{O}$ a veces meramente sugeridos-. Aquí, de nuevo, la variabilidad es mucha en nuestro corpus, dentro de los límites marcados por unas características comunes -que también son significativas- de dispersión de los eventos contados.

Por ejemplo, he aquí un cuento con una coherencia escasa:

Que després hi havia una nena i després estava un, una mamá. Després passava que hi havia un caballo xicotet i després estava su papá. I després van buscar caramelos. I després van a jugar en les nines. Que després va a passar que se van a meter al agua. Que el agua és una piscina. Que hi havia peixets, sí, pero molt xicotets pa que no se mossega. Que, que, que després hi havia un munt de, que hi havia un cotxe de bomberos. Que van a salvar-li

\footnotetext{
${ }^{6}$ Que salía una araña que era muy pequeñita y era roja. Pues yo toqué una de color rojo a los columpios, pero no, pero no lloré porque la araña tenía las patas de color naranja. Pero a mí no me gusta la araña de color rojo. Yo la quería matar. Que yo, yo... que yo no la maté. Que salió un gusano y se comió a la araña. Que salió una cebra y se fue con el gusano. Y salió un calamar y encontró un oso y se fue con el oso y comieron con el calamar un kiwi. Que saldría una vaca que ponía leche encima de la cebra blanca y negra. [...] Que salía una fresa y un gusano se comió la fresa y la araña también. Que salió una fresa y el oso también se comió la fresa y la cebra también. Y entonces la araña se comió a la cebra y la cebra estaba "morida". Que la araña también se comía las piernas y las orejas, y también la cola y el culo.
} 
al gat. I después van anar al, como esta piscina. Que si va pasar que era, si no, això que és, era una tirita que se ha fet mal una nena, perquè té una tirita la seua mamá. Ja està. (Ya núm. 1)

El siguiente cuento, en cambio, muestra una lógica muy clara -a pesar de la dilación en la acción reiterativa-, con una evidente resolución del evento, basada en experiencias comunes de la infancia -se trata de un final triste-:

La classe dels elefants se va llimpiar el cap con champú. I allavontes se'n va a la banyera i se llimpia. I s'ha entrompessat en un xarco. Allavontes se va dutxar una altra vegada. Los elefants van veure otro xarco delante. Se van tropessar. Se van dutxar. I se van tropessar a una aigua. I... Los elefants tenen una mama, la mama le van donar al culo. I la mama se va enfadar, i allavontes los va castigar a los elefants. Los tancava allà fora. No los dixava entrar. Son grandes. [...] I los van castigar. (Adr núm. 1)

\subsubsection{Cohesión}

La cohesión del relato infantil se puede medir del mismo modo en que se suele hacer en los análisis del discurso en edades adultas. La presencia de marcadores o conectores discursivos es vital en este factor, pero también se hace preciso analizar la claridad de los sujetos gramaticales, y de los antecedentes sintácticos y referentes semánticos de los pronombres. Hay que tener en cuenta que la habilidad para mantener la referencialidad de los personajes de un relato puede estar condicionada por múltiples factores, incluyendo el propio idioma (Aksu-Koç y Nicolopoulou, 2014). Fundamentalmente es el desarrollo lingüístico acorde con la edad, el determinante de la complejidad sintáctica en las narraciones infantiles, así como en otros géneros discursivos (Ow y Alvarado, 2013). En 3-4 años, la sensación al escuchar un relato infantil de estas edades puede fluctuar entre "me

\footnotetext{
${ }^{7}$ Que después había una nena y después estaba un, una mamá. Después pasaba que había un caballo pequeñito y después estaba su papá. Y después fueron a buscar caramelos. Y después fueron a jugar con las muñecas. Que después pasó que se metieron al agua. Que el agua es una piscina. Que había pececitos, sí, pero muy pequeñitos para que no se muerda. Que, que, que después había un montón de, que había un coche de bomberos. Que van a salvarle al gato. Y después fueron al, como esta piscina. Que si pasó que era, si no, esto que es, era una tirita que se ha hecho daño una nena, porque tiene una tirita su mamá. Ya está.

${ }^{8}$ La clase de los elefantes se limpió la cabeza con champú. Y entonces se fue a la bañera y se limpia. Y se ha tropezado en un charco. Entonces se duchó otra vez. Los elefantes vieron otro charco delante. Se tropezaron. Se ducharon. Y se tropezaron en un agua. Y... Los elefantes tienen una mamá, la mamá les dio al culo. Y la mamá se enfadó, y entonces los castigó a los elefantes. Los enceraba allá fuera. No los dejaba entrar. Son grandes. [...] Y los castigaron.
} 
pierdo y no sé de qué me está hablando" -en este ejemplo ya mencionado, la falta de cohesión se encuentra en los sujetos no explícitos, no en el buen uso de conectores-:

Que un caballito se iba a buscar una cesta. Y después, después iba pel bosc i va encontrar un llop. Pero después va anar a... después va anar a encontrar un bebé de juguete. Que después va encontrar una floreta. Que va encontrar un Piolín. Que después encontraba números, como aquella (señala las láminas de números en la pared) $1,2,3,4,5,6,7,8,9 \ldots$ Que después encontraba un tomate y un helicóptero. (¿Era el lobo o el caballito que encontraba cosas?) El llop. [...] (Cl núm. 2)

Hasta narraciones con intentos mucho más conscientes de cohesión gramatical, no obstante la falta de lógica que pueda existir en el relato:

[...] Alexia té una pissarra i tenim paper pa borrar la pissarra. És de Alexia. I, i i tenim uns colors de guixos. Lo té Alexia. Demà te'l ensenyaré. Natros tenim un... Ara ha sortit un caragol, ara no. Ha sortit a casa i no el tenim ara el caragol (¿Se ha ido con sus amigos?) Si, a la escola. El caragol s'ha anat a escola. I no té mans per al llibre. Lo caragol no té mans perquè volia un 1libre. (Ei núm. 2)

\subsubsection{Habilidad discursiva y pragmática}

El nivel pragmático del lenguaje nos parece un factor influyente en la mayor o menor complejidad de las narraciones producidas por los niños. Entendemos por tal todo lo englobado por la teoría pragmática y aceptado sin ambages en la lingüística contemporánea (teorías de Grice, Austin, Searle, etc), más la interpretación y adecuación del texto al contexto, según la teoría de Van Dijk. A fin de cuentas, producir un hecho literario es realizar una acción en un contexto que implica, además, a diferentes personas. La habilidad discursiva y pragmática se ha querido concretar en nuestra muestra en el uso del lenguaje evaluativo, elemento clave en las narraciones. Cuando los niños se enfrentan al hecho de narrar, no solamente lo hacen desde la perspectiva de secuenciación o encadenamiento de eventos, sino que intervienen factores paralingüísticos y expresivos del lenguaje que consideramos de gran interés como componente estructural de las narraciones,

\footnotetext{
${ }^{9}$ [...] Alexia tiene una pizarra y tenemos papel para borrar la pizarra. Es de Alexia. Y, y, y tenemos unos colores de tizas. Lo tiene Alexia. Mañana te lo enseñaré. Nosotros tenemos un... Ara ha salido un caracol, ara no. Ha salido a casa y no lo tenemos ahora el caracol. Sí, a la escuela. El caracol se ha ido a la escuela. Y no tiene manos para el libro. El caracol no tiene manos porque quería un libro.
} 
dotando de sentido a la historia al referenciar motivos, sentimientos y reacciones, tanto de los personajes como del narrador. Así pues, consideramos que la situación comunicativa influye en la interpretación de la narración y la dota de significado.

Asumiendo que, en general, los niños hacen un uso escaso del lenguaje evaluativo en sus narraciones hasta los seis años (Bamberg y Reilly, 1996; Romero y Gómez, 2013), hemos advertido que, en ocasiones, a través del uso del estilo directo -voz en primera persona de los personajes- los niños eran capaces de expresar actitudes, emociones y estados internos de los personajes; esto supone un control mayor sobre el discurso narrativo, que hemos creído imprescindible evaluar. Mostramos un ejemplo:

[...] Hi havia un de Hawai i un xino, però és de un altre monstruo, un fantasma és. Va y dice ¿Me podría dar una habitación salvada por mí? Y diu: está encantada por un monstruo. I va, agafa un martillo i li fot al cap, a tot el tornillo. [...] (Gu núm. 2) ${ }^{10}$

En otros relatos observamos el uso del estilo indirecto -la voz en tercera persona-:

[...] Que, que, que lo caballo va sortir corrents i se'n va anar a casa. Pero si que va vindre lo llop. Que va obrir la porta de lo caball i li va dir al llop que no entreu. I los caballos van dir que no entrés lo llop. [...] Que, que se va trovar a un ratolí taronja i lo ratolí li va dir que no entreu perque no entren los ratolins a la casa de los caballos. [...] Pero la seua mama de los caballos no le dixen entrar a los caballos. I la mama de los caballos se va enfadar. Que, que van plorar los ratolins pero van vindre uns atres ratolins i van curar a los altres ratolins. I un monstruo se va minjar a los altres ratolinets. I, i va vindre un altre monstruo que no minjava ratolins. Que, que arrivaria un altre monstruo que era amic del altre monstruo. I después los monstruos van dir que no entreu a la casa de los caballos. Ja s'ha acabat lo conte. (Me núm. 2) ${ }^{11}$

${ }^{10}[\ldots]$ Había uno de Hawai y un chino, pero es de otro monstruo, un fantasma es. Va y dice ¿Me podría dar una habitación salvada por mí? Y dice: está encantada por un monstruo. I va, coge un martillo i le arrea a la cabeza, en todo el tornillo. [...]

${ }^{11}$ [...] Que, que, que el caballo salió corriendo y se fue a casa. Pero sí que vino el lobo. Que abrió la puerta del caballo y le dijo al lobo que no entrara. Y los caballos dijeron que no entrara el lobo. [...] Que, que se encontró un ratoncillo naranja y el ratoncillo le dijo que no entraran porque no entran los ratones a la casa de los caballos. [...] Pero su mamá de los caballos no le dejan entrar a los caballos. Y la mamá de los caballos se enfadó. Que, que lloraron los ratones pero vinieron otros ratones y curaron a los otros ratones. Y un monstruo se comió a los otros ratones. Y, y vino otro monstruo que no comía ratones. Que, que 
Y en otros se acompaña la voz por gestos que refuerzan la situación comunicativa y proporcionan significado a la narración, mostrando el conocimiento que tiene el narrador sobre los personajes; anotamos los rasgos quinésicos entre paréntesis:

[...] Va caure en una aigua, se van dutxar i, i li va entrar aigua pel nas i, i va fer així (hace una pedorreta con la boca e imita con el brazo la trompa del elefante) i, i, i se va xopar tot. Se, se va enfadar la mama (pone cara de enfadado) i los va castigar als elefants, y va, y va... le va dar la volta a la llave (con la mano imita el movimiento de cerrar con llave) i no podían entrar. I ha fet així (simula con la mano que llama a la puerta) i no ha vingut la mama i estava dormida i no ha ido a la porta. I estaba sola i no va oir. [...] (Adr núm. 2) ${ }^{12}$

\subsubsection{Soltura}

La soltura a la hora de narrar se puede medir a través de la fluidez y comodidad del niño mientras nos cuenta el cuento. Este factor se ha podido registrar y analizar gracias a las grabaciones de vídeo realizadas en el experimento. Tenemos que tener en cuenta uno de los factores comentados en el punto 3.2, en referencia a la posición para contar. Podríamos haber obtenido resultados distintos si hubiéramos dado total libertad al niño para moverse por la sala y, aunque nuestras instrucciones fueron que permanecieran sentados, hubo niños que se levantaron para señalar objetos presentes en las láminas que había en la sala, mostrando así su necesidad de movimiento para crear, tal y como mostramos con este ejemplo:

[...] Un policia. Hi ha un pare, un pare i un nene. I un peix, un peix. I això? (señala los dibujos de la puerta y se levanta) Mira: la mama, esta és la mama, esta, vale? I ara la mama esta, vale? Està aquí la mama esta, i ara esta aquí. (Coge las láminas pegadas en la puerta y las cambia de sitio) I este policía, aquí (se le cae una lámina al suelo) Ai, ai, ai... Esta no, al revés (colocamos

llegaría otro monstruo que era amigo del otro monstruo. Y después los monstruos dijeron que no entráis a la casa de los caballos. Ya se ha terminado el cuento.

${ }^{12}$ [...] Cayó en un agua, se ducharon y, y le entró agua por la nariz y, e hizo así y, y, y se mojó todo. Se, se enfadó la mamá y los castigó a los elefantes, y va, y va... le va dar la vuelta a la llave y no podían entrar. I ha hecho así y no ha venido la mamá y estaba dormida y no ha ido a la puerta. Y estaba sola y no va oír. [...] 
las láminas y le hago volver a su sitio). (Señala las imágenes) Un pare (se vuelve a levantar y le vuelvo a hacer sentar) i caballos. [...] (Ad núm. 2) ${ }^{13}$

Por otra parte, la brevedad de las pausas y las interrupciones -duración en relación con la longitud- nos ofrecieron datos para valorar la comodidad y soltura del niño al narrar. Los niños usaban dichas pausas básicamente con tres fines: para pensar lo que tenían que decir, para mirar a su alrededor e inspirarse en las imágenes que había en la sala a la hora de crear los personajes y los temas de sus narraciones, o bien esperaban la aprobación de la maestra para continuar con la narración.

En los cuentos número 2, respecto a los cuentos número 1, los niños mostraron mayor soltura al disminuir el uso de pausas significativas. Todo ello proporcionó, en algunos casos, relatos más fluidos. Por otra parte, dicha fluidez pudo ser debida a que, en la mayoría de los casos, los niños utilizaron el mismo tema y los mismos personajes que en el cuento 1 .

\section{PROPUESTA DE MODELO DE ANÁLISIS}

Tras comparar y valorar los modelos de análisis propuestos por los autores mencionados en este estudio, proponemos ahora un modelo de análisis que nos ha permitido cuantificar con mayor fidelidad la complejidad de las narraciones que se han recogido en este trabajo y concluir con un ensayo sobre una posible estructuración o categorización de las narraciones infantiles a los 3-4 años de edad, que detalle de una forma más completa la descripción de cada uno de los estadios de desarrollo de habilidades narrativas a estas edades.

El modelo de análisis que proponemos, basado en los factores e indicadores mencionados en el apartado anterior, se adapta perfectamente a nuestro corpus. Para cuantificar las narraciones, utilizamos un sistema de puntuación similar al del modelo ofrecido por Heilmann et al. (2010). Así pues, valoramos con una puntuación entre 0 y 5 por cada uno de los siete apartados -Tabla 4-, identificando la mayor o menor aproximación al logro de cada factor. La suma final estaría entre una puntuación de 0 a 35 . Dicha puntuación debe ser dinámica y es totalmente orientativa, ya que lo más adecuado sería establecer una valoración adaptada al corpus trabajado en cada estudio; nuestra experiencia así lo demuestra.

${ }^{13}$ [...] Un policía. Hay un padre, un padre y un nene. Y un pez, un pez. ¿Y esto? Mira: la mamá, esta es la mamá, esta, ¿vale? Y ahora la mamá esta, ¿vale? Está aquí la mamá esta, y ahora está aquí. Y este policía, aquí. Ay, ay, ay... Esta no, al revés. Un padre y caballos. $[\ldots]$ 
Tabla 4. Factores e indicadores vinculados a las narraciones

- Produce un relato / Produce una enumeración o una descripción. / No produce ningún relato -aunque puede

1. Comprensión y control del género ser una canción memorizada textualmente, o similar-.*

- Un único relato / Varios mini-relatos como secuencias aislables sin desarrollar plenamente ni enlazar.

- Título o fórmula de inicio / No.

- Fórmula de final / No.

- Relatos sobre personajes ficticios o ajenos a su experiencia / Relatos de su experiencia con el autor como personaje -o sus familiares, o personas de su entorno más 2. Ficcionalización próximo-.

- Relatos originales de creación propia / Incorporación de intertextualidades en relatos originales / Variaciones y versiones propias de secuencias de cuentos conocidos.

\begin{tabular}{|c|c|}
\hline 3. Complejidad & $\begin{array}{l}\text { - Longitud -número de palabras-. } \\
\text { - Número de personajes. } \\
\text { - } \text { Detalles en la descripción de personajes y en la } \\
\text { ambientación. } \\
\text { - Existencia de líneas secundarias en la trama. }\end{array}$ \\
\hline 4. Coherencia & $\begin{array}{l}\text { - Los eventos siguen un orden lógico-cronológico / No, y } \\
\text { hay contradicciones. } \\
\text { - Existen transiciones fluidas entre las secuencias / No. } \\
\text { - } \text { Los conflictos que aparecen se resuelven / No. }\end{array}$ \\
\hline 5. Cohesión & $\begin{array}{l}\text { - Están claros los sujetos de las acciones / No. } \\
\text { - Los pronombres tienen un antecedente o referente claro / } \\
\text { No. } \\
\text { - Uso de conectores discursivos. }\end{array}$ \\
\hline $\begin{array}{l}\text { 6. Habilidades } \\
\text { pragmáticas y } \\
\text { discursivas }\end{array}$ & $\begin{array}{l}\text { - Lenguaje evaluativo: } \\
\text { - Refleja actitudes, emociones y estados internos de los } \\
\text { personajes. } \\
\text { - Voces en las narraciones: estilo directo / estilo } \\
\text { indirecto. } \\
\text { - Rasgos quinésicos: gestos que acompañan la voz y }\end{array}$ \\
\hline
\end{tabular}




\begin{tabular}{l|l}
\hline & refuerzan la situación comunicativa. \\
\hline 7. Soltura & $-\begin{array}{l}\text { Fluidez y comodidad narrando -vídeo- / Sólo comienza o } \\
\text { prosigue cuando se le pide, y/o manifiesta que desea } \\
\text { marcharse. }\end{array}$ \\
$-\begin{array}{l}\text { Brevedad de las pausas y las interrupciones -duración en } \\
\text { relación con la longitud-. }\end{array}$
\end{tabular}

* Este indicador limita en realidad la posterior calificación de la producción del niño. En caso de que no produzca un relato, se extrae del corpus y no se analiza. Las enumeraciones y las descripciones sí se consideran formas iniciales de la narración.

Mostramos en la Tabla 5 las puntuaciones obtenidas en nuestro modelo de análisis:

Tabla 5. Calificaciones según nuestro modelo

\begin{tabular}{|c|c|c|c|}
\hline & Edad & Cuento 1 & Cuento 2 \\
\hline Ad $\sigma^{\lambda}$ & $3 ; 4$ & 7 & 9 \\
\hline $\operatorname{Adr} \sigma^{\lambda}$ & $3 ; 9$ & 24 & 28 \\
\hline $\mathbf{A i}+q$ & $4 ; 2$ & 11 & 10 \\
\hline Ca 9 & 4 & 0 & 9 \\
\hline Cl 9 & $3 ; 11$ & 25 & 21 \\
\hline $\mathbf{E i}$ ㅇ & $3 ; 4$ & 8 & 18 \\
\hline El $q$ & $3 ; 5$ & 14 & 29 \\
\hline Gu ${ }^{\lambda}$ & $4 ; 1$ & 12 & 19 \\
\hline Ia $\sigma^{\lambda}$ & $3 ; 4$ & 8 & 7 \\
\hline Jo ${ }^{\lambda}$ & $3 ; 6$ & 13 & 0 \\
\hline $\mathbf{J u}+$ & $3 ; 10$ & 11 & 10 \\
\hline Ke ${ }^{\hat{\sigma}}$ & $3 ; 4$ & 23 & 23 \\
\hline La 9 & $3 ; 8$ & 0 & 12 \\
\hline Ma ${ }^{\lambda}$ & $3 ; 10$ & 9 & 12 \\
\hline Me 9 & $3 ; 5$ & 26 & 31 \\
\hline $\operatorname{Ra} \sigma^{\lambda}$ & $3 ; 7$ & 18 & 17 \\
\hline RA $\sigma^{\lambda}$ & $4 ; 2$ & 0 & 0 \\
\hline $\mathbf{Y a}$ ㅇ & $3 ; 8$ & 17 & 17 \\
\hline
\end{tabular}

\subsection{Contraste de datos}

Para comparar debidamente las puntuaciones obtenidas en los modelos usados para calificar las narraciones y el nuestro propio, nos dispusimos a convertir todas 
las puntuaciones a escala de $0-10$. De este modo observamos de forma más clara las diferencias y similitudes entre ellos.

Tabla 6. Puntuaciones a escala de 0-10 -A: Applebee; L: Landaeta et al.; H: Heilmann et al.; M: Monforte-Ceballos-

\begin{tabular}{|c|c|c|c|c|c|c|c|c|c|}
\hline & & \multicolumn{4}{|c|}{ Cuento 1} & \multicolumn{4}{|c|}{ Cuento 2} \\
\hline & Edad & $\mathbf{A}$ & $\mathbf{L}$ & H & M & $\mathbf{A}$ & $\mathbf{L}$ & H & $\mathbf{M}$ \\
\hline $\operatorname{Ad} \sigma^{\lambda}$ & $3 ; 4$ & 1.66 & 2.30 & 2 & 2 & 1.66 & 2.30 & 2.28 & 2.57 \\
\hline $\operatorname{Adr}{ }_{0}^{\lambda}$ & $3 ; 9$ & 5.80 & 6.15 & 5.71 & 6.85 & 5.80 & 8.46 & 5.42 & 8 \\
\hline $\mathbf{A i} q$ & $4 ; 2$ & 5 & 3.84 & 4 & 3.14 & 3.33 & 3.07 & 3.14 & 2.85 \\
\hline Ca 9 & 4 & 0 & 0.76 & 0 & 0 & 1.66 & 2.30 & 2.28 & 2.57 \\
\hline Cl $\stackrel{1}{+}$ & $3 ; 11$ & 3.33 & 3.84 & 5.14 & 7.14 & 5 & 3.07 & 3.71 & 6 \\
\hline $\mathbf{E i}$ 운 & $3 ; 4$ & 1.66 & 3.07 & 2.28 & 2.28 & 3.33 & 3.84 & 4.85 & 5.14 \\
\hline El $q$ & $3 ; 5$ & 3.33 & 2.30 & 3.42 & 4 & 5 & 8.46 & 5.42 & 8.28 \\
\hline Gu ${ }^{\hat{\alpha}}$ & $4 ; 1$ & 3.33 & 3.07 & 4 & 3.42 & 5 & 3.84 & 4.28 & 5.42 \\
\hline Ia $\hat{O}$ & $3 ; 4$ & 1.66 & 2.30 & 2.28 & 2.28 & 1.66 & 1.53 & 2.57 & 2 \\
\hline Jo ${ }^{\lambda}$ & $3 ; 6$ & 5 & 1.53 & 3.71 & 3.71 & 0 & 1.53 & 0 & 0 \\
\hline $\mathbf{J u} q$ & $3 ; 10$ & 5 & 2.30 & 2.57 & 3.14 & 1.66 & 1.53 & 2.57 & 2.85 \\
\hline $\operatorname{Ke}{ }^{\lambda}$ & $3 ; 4$ & 6.66 & 6.15 & 4.85 & 6.57 & 6.66 & 6.15 & 5.42 & 6.57 \\
\hline La $ㅇ$ & $3 ; 8$ & 0 & 0.76 & 0 & 0 & 3.33 & 3.07 & 3.42 & 3.42 \\
\hline Ma $\hat{O}$ & $3 ; 10$ & 1.66 & 2.30 & 2.28 & 2.57 & 1.66 & 2.30 & 3.71 & 3.42 \\
\hline Me 9 & $3 ; 5$ & 5.80 & 6.92 & 5.14 & 7.42 & 5.80 & 6.92 & 6 & 8.85 \\
\hline $\operatorname{Ra}{ }^{\lambda}$ & $3 ; 7$ & 2.50 & 3.07 & 3.14 & 5.14 & 3.33 & 3.07 & 3.71 & 4.85 \\
\hline RA $\sigma^{\lambda}$ & $4 ; 2$ & 0 & 0.76 & 0 & 0 & 0 & 0.76 & 0 & 0 \\
\hline $\mathbf{Y a}$ ㅇ & $3 ; 8$ & 2.50 & 3.07 & 4 & 4.85 & 3.33 & 3.84 & 4.57 & 4.85 \\
\hline
\end{tabular}

Obtenemos para cada modelo de análisis las siguientes medias $\left[x_{1}+x_{2}+\cdots+x_{36}\right] / 36-:$ A, 3.14 puntos; L, 3.35 puntos; H, 3.27 puntos; y M, 3.95 puntos. En nuestra opinión, el dato de nuestro modelo es más elevado porque hemos considerado factores nuevos que los otros modelos ignoraban, en los que los niños manifiestan competencias potencialmente más desarrolladas -como la soltura o las habilidades discursivas y pragmáticas-. Así pues, este ascenso en la puntuación refleja, creemos, una mayor precisión en el análisis multifactorial de las narrativas infantiles.

La mediana -puntuación por debajo de la cual se encuentra el 50\% de los datoses similar en todos los modelos, el $50 \%$ de los cuentos se encuentran por debajo de los 3.42 puntos en nuestro modelo -A: 3.33; L: 3.07; H: 3.56-.

Hemos calculado las frecuencias absolutas en cada uno de los modelos para observar cuál ha sido el dato de mayor frecuencia -moda-. Podemos ver los resultados en las siguientes figuras: 
Figura 5. Frecuencia absoluta modelo $A$

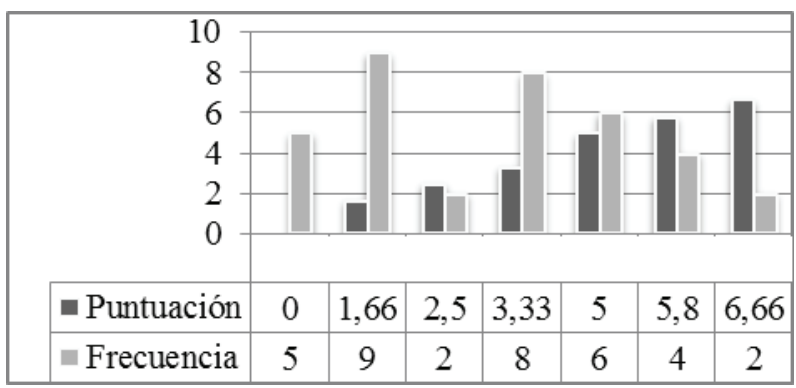

Figura 6. Frecuencia absoluta modelo L

\begin{tabular}{|c|c|c|c|c|c|c|c|c|}
\hline \multicolumn{9}{|l|}{10} \\
\hline 8 & & & & & & & & \\
\hline 6 & & & & & & & & \\
\hline 2 & & $\Rightarrow$ & & - & & & & \\
\hline & & & & & & & & \\
\hline - Puntuación & 0,76 & 1,53 & 2,3 & 3,07 & $7 \quad 3,84$ & 6,15 & 6,92 & 8,46 \\
\hline Frecuencia & 4 & 4 & 8 & 8 & 5 & 3 & 2 & 2 \\
\hline
\end{tabular}

En el modelo A -Figura 5- el dato de mayor frecuencia es 1.66, puntuación obtenida por 9 de los 36 cuentos. En el modelo L -Figura 6- son dos las puntuaciones que más se repiten -2.30 y 3.07 - en igual número de cuentos.

En la Figura 7 -modelo $\mathrm{H}$ - el dato de mayor frecuencia se corresponde con la puntuación de 2.28, de los 36 cuentos, 5 obtuvieron dicha puntuación. Por otra parte, se observa un empate en frecuencia con los casos en los que hubo ausencia de relato, que valoramos con un 0 .

Figura 7. Frecuencia absoluta modelo $\mathrm{H}$

\begin{tabular}{rr|r|r|c|c|c|c|c|c|c|c|c|c|c|c|}
\hline 8 \\
\hline 6
\end{tabular}


Finalmente, en nuestro modelo de análisis -Figura 8-, se observa más variabilidad en los datos, resultado -en parte- del mayor detalle de las variables presentes en el análisis -a más variables, mayor complejidad y gradación de datos. Así, coinciden en frecuencia las puntuaciones 2.57, 3.42 y 4.85 .

Figura 8. Frecuencia absoluta modelo M

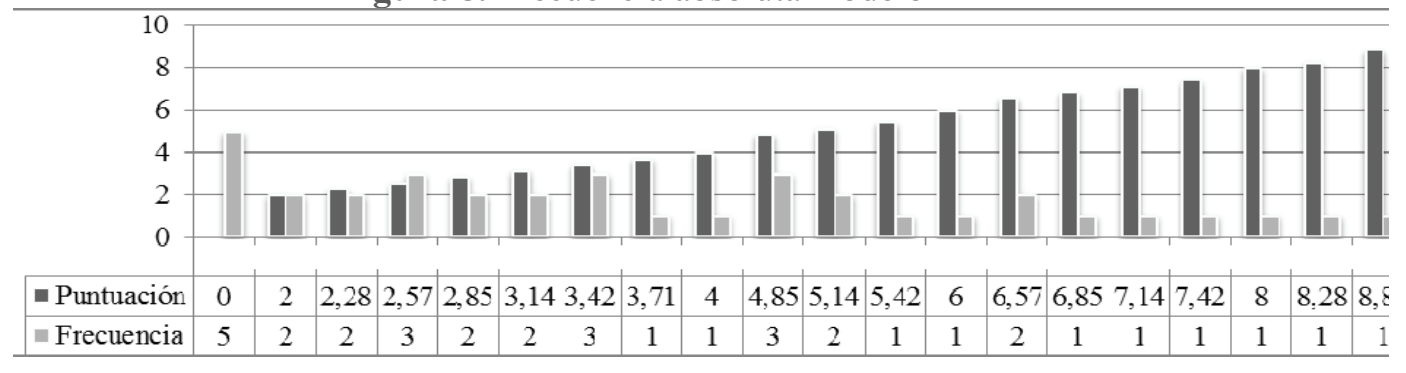

El grado de dispersión de los datos -varianza- resulta muy alto en los modelos L -18.92- y el nuestro $\mathrm{M}-15.70-$, alejándose los valores mucho de la media. Por el contrario, en los modelos A -7.78- y H -5.77-, aunque no lo consideraríamos un grado de dispersión bajo, se alejarían menos puntos por debajo de la media. Las desviaciones típicas son en consecuencia, relativamente bajas en los modelos $\mathrm{A}-$ 2.79- y H -2.40-, si las comparamos con los modelos L -4.35- y M -3.96-, donde encontramos los datos más dispersos.

Por otra parte, se ha calculado el coeficiente de correlación entre nuestro modelo y cada uno de los demás modelos, siendo en todos los casos un coeficiente alto, ya que es superior a $0.80-\mathrm{M}-\mathrm{A}$ : 0.86; M-L: 0.89; M-H: 0.94-. Se ha comprobado que cuando la puntuación en nuestro modelo aumenta o disminuye, en los otros modelos también varía en el mismo sentido -la correlación es positiva-, obteniendo calificaciones similares. Este dato se puede interpretar como verificación de la validez de nuestro nuevo modelo propuesto y de la fiabilidad de nuestro análisis. Dicha congruencia avala, creemos, nuestro intento por perfilar y detallar mejor el análisis de las narrativas infantiles basándonos -sin menospreciarlos- en los modelos anteriores.

\section{CONCLUSIONES E IMPLICACIONES DIDÁCTICAS}

En este artículo hemos pretendido dar una vuelta de tuerca más en el estudio de las producciones narrativas orales en la primera infancia. Conscientes de que se trata de un tema complejo, hemos atendido a lo más representativo de los estudios precedentes para, basándonos en ellos, analizar nuestra muestra de 36 relatos producidos por niños de 3 y 4 años. El propio proceso de análisis, como hemos comentado, nos llevó a cuestionar la completa validez de los modelos y esquemas 
previos, y a desarrollar consecuentemente nuestro propio modelo multifactorial, que atendía a un total de 22 variables -indicadores-. Este modelo, que denominamos, a falta de un nombre más preciso, modelo Monforte-Ceballos, añade aspectos que se mostraron relevantes en el estudio de nuestro corpus -la soltura verbal y gestual del niño al narrar, o la determinación de su control y conocimiento de las características del género narrativo- y aglutina y precisa muchos de los indicadores considerados por otros autores - estructura lógica de la narración, referencialidad gramatical adecuada, resolución de los conflictos, uso del lenguaje evaluativo, etc.-.

La calificación del corpus de cuentos infantiles según cuatro modelos de puntuación -Applebee, Landaeta et al., Heilmann et al., y el nuestro propio-, seguida del contraste entre las puntuaciones obtenidas en unos y otros, ha revelado que los resultados son coherentes en líneas generales entre todos ellos, obteniendo correlaciones positivas altas. Esto supone, a nuestro juicio, que el modelo Monforte-Ceballos, que es más amplio y exhaustivo, desarrolla la línea de los estudios precedentes y avanza un paso más allá en la caracterización narrativa de los cuentos infantiles. Por supuesto, y dicho sea de paso, somos conscientes de que este modelo puede resultar ineficaz aplicado a diferentes contextos culturales, en los que el estereotipo ideal de una buena narración difiera del nuestro -véase el interesante estudio de Peltier, 2014-.

Damos así por alcanzado el objetivo que nos planteábamos al comienzo de nuestra experimentación. Al poseer un modelo de análisis eficaz para estos relatos, apuntamos a la consecución de ciertos beneficios didácticos. En primer lugar, en el ámbito de las producciones lingüísticas en la primera infancia, será más clara la evaluación de este tipo de emisiones, permitiendo ubicar en una escala las que mejor o peor concuerdan con el desarrollo de las capacidades narrativas adecuadas a su edad. En segundo lugar, el conocimiento más profundo de las estructuras de los relatos que inventan los niños arroja un haz de luz sobre el tipo de narraciones que, consecuentemente, son capaces de entender, de modo que esto aportará ciertas claves para una mejor selección de los relatos que los maestros han de dirigir a sus alumnos en tanto que receptores de la comunicación literaria. Esperamos haber contribuido acertadamente a este campo de estudio, prácticamente inexistente en nuestro país, y auguramos su desarrollo y utilidad para los estudios del desarrollo del lenguaje infantil y para la didáctica de la literatura en las primeras etapas.

Finalmente, queremos dejar un frente abierto que nos permita elaborar, en futuras investigaciones, una posible estructuración o categorización por estadios de desarrollo narrativo, utilizando el presente estudio como base para su desarrollo. Con todo ello pretendemos clasificar los relatos obtenidos en nuestro corpus dentro de un modelo de estructuras narrativas que establezca grupos de menor a mayor complejidad narrativa y adaptarlo, aún más si cabe, a la franja de edad de tres a cuatro años. Aunque sabemos que esta va a ser una tarea complicada, puesto que 
disponemos de relatos muy heterogéneos, consideramos de gran importancia el seguir investigando en este campo.

\section{BIBLIOGRAFÍA}

AKSU-KOÇ, Ayhan y NICOLOPOULOU, Ageliki (2014): “Character Reference in Young Children's Narratives: A Crosslingüistic Comparison of English, Greek and Turkish", Lingua, en prensa.

APPLEBEE, Arthur (1978): The Child's Concept of Story, Chicago - London, University of Chicago Press.

BAMBERG, M. y REILLY, J. (1996): "Emotion, Narrative, and Effect: How Children Discover the Relationship between What to Say and How to Say It", en Social Interaction, Social Context and Language, SLOBIN, D., GERHARDT, J., KYRATZIS, A. y GUO, J. (Eds.), Hillsdale (NJ), Lawrence Erlbaum, 329-341.

BRUNER, Jerome (1988): Realidad mental y mundos posibles: los actos de la imaginación que dan sentido a la experiencia, Barcelona, Gedisa, 2001.

CHUKOVSKY, Kornei (1971): From Two to Five, Berkeley - Los Angeles London, University of California Press.

HEATH, Shirley (1986): "Taking a Cross-Cultural Look at Narratives", en Topics in Language Disorders, 7 (1): 84-94.

HEILMANN, John, MILLER, Jon F., NOCKERTS, Ann (2010): "Sensitivity of Narrative Organization Measures Using Narrative Retells Produced by Young School-Age Children", en Language Testing, 27:4, 603-627.

HUDSON, Janet y SHAPIRO, Lauren (1991): "From Knowing to Telling: The Development of Children's Scripts, Stories and Personal Narrative", en Developing narrative structure, McCABE, A. y PETERSON, C. (Eds.), Hillsdale (NJ), Lawrence Erlbaum, 89-136.

LANDAETA, Mariangela M., COLOMA, Carmen Julia y PAVEZ, Ma Mercedes (2009): "Estimulación de narraciones infantiles", en Revista CEFAC Atualizaçao Cientifica em Fonoaudiologia e Educaçao, 11:3, 379-388.

OW, Maili y ALVARADO, Carola (2013): "Niños que narran: aumento en la complejidad discursiva y sintáctica durante la edad escolar", en Literatura y lingüistica, 28, 149-168.

PELTIER, Sharla (2014): “Assessing Anishinaabe Children's Narratives: An Ethnographic Exploration of Elder's Perspectives", en Canadian Journal of Speech-Language Pathology and Audiology, 38:2, 174-193.

PETERSON, Carole y McCABE, Allyssa (1983): Developmental Psycholinguistics, New York: Plenum Press.

REILLY, J., LOSH, M. BELLUGI, U. y WULFECK, B. (2004): "Frog, Where Are You? Narratives in Children with Specific Language Impairment...”, en 
Plasticity and Development: Language in Atypical Children, WULFECK, B. y REILLY, J. (Eds.), (Brain \& Language, Special Issue, 88:2), 229-247.

RODARI, Gianni (1973): Gramática de la fantasía, Madrid, Planeta, 2006.

ROMERO, Silvia y GÓMEZ, Gloria E. (2013): "El desarrollo del lenguaje evaluativo en narraciones de niños mexicanos de 3 a 12 años", en Actualidades en Psicología, 27:115, 15-30.

SHIRO, Martha (2011): El desarrollo de los géneros en el habla infantil: el caso de la narración, Caracas, Universidad Central de Venezuela.

STEIN, Nancy L. (1988): "The Development of Storytelling Skill”, en Child Language: A reader, FRANKLIN, M. y BARTEN, S. (Eds.), New York, Oxford University Press, 282-297.

VYGOTSKI, Lev (1981): Pensamiento y lenguaje, Buenos Aires, La Pléyade. 